\title{
The Effect of Heat Treatment on the Properties of Ultra High Strength Concrete
}

\author{
Girts Bumanis, Nikolajs Toropovs, Laura Dembovska, Diana Bajare, Aleksandrs Korjakins \\ Riga Technical University, Faculty of Civil Engineering, Department of Building Materials and \\ Products. Address: Azenes Street 16, Riga, LV-1658, Latvia
}

\begin{abstract}
The influence of heat treatment during curing process of ultra high strength concrete (UHSC) was researched. Four different heat treatment temperatures ranging from 50 to $200^{\circ} \mathrm{C}$ were studied and compared to the reference temperature regime $\left(20^{\circ} \mathrm{C}\right)$. Two series of heat treatment were applied: (a) at the early age of UHSC ( 3 days) and (b) after 27 days of standard curing regime in water at $20^{\circ} \mathrm{C}$. Concrete compressive strength was tested at the early age (4 days) and at the age of 28 days. The water absorption and water penetration under pressure were tested for heat treated and untreated UHSC specimens. SEM and XRD investigations of the studied samples were performed. UHSC with the strength of $123 \mathrm{MPa}$ at the age of 28 days was tested at the standard curing conditions. Results indicate that early age curing at elevated temperature increases early compressive strength from 123 to $189 \%$ while at the age of 28 days the compressive strength was only 95 to $117 \%$ from reference and depends on the heat treatment regime. The heat treatment of UHSC at the age of 27 days was beneficial with regard to the strength development. Heat-treated UHSC provided compressive strength gain from 112 to $124 \%$ from reference. The water absorption for all UHSC specimens was from 2.6 to $3.2 \mathrm{wt} . \%$ and it was not affected by the heat treatment. The calcite was detected with XRD in heat treated UHSC samples which indicates the carbonization of Portlandite. This could explain the strength gain of heat-treated samples and the reason for slow compressive strength increase in the case of early heat treatment application. SEM images reveal dense structure and unreacted silica fume particles. The early heat treatment initiated high early strength but the strength of concrete reduced at the age of 28 days comparing to the early strength; therefore late heat application was beneficial for strength gain of the UHSC.
\end{abstract}

Keywords: curing conditions, heat treatment, ultra high performance concrete.

\section{INTRODUCTION}

In the concrete industry ultra high strength concrete (UHSC) is a result of logical evolution process of traditional concrete and high strength concrete (HSC). UHSC is characterised with high binder content and reduced aggregate size and water to cement (or cement paste) ratio below 0.25 which allows obtaining material without capillary porosity. The compressive strength of UHSC exceeds $150 \mathrm{MPa}$ [1]. To obtain UHSC effective micro and nano fillers such as pozzolans or supplementary cementitious materials have to be used. Incorporation of the above mentioned fillers which contain amorphous $\mathrm{SiO}_{2}$ additives (i.e. micro and nano silica) in the mixture composition of concrete reduces the amount of Portlandite $\mathrm{Ca}(\mathrm{OH})_{2}$ and $\mathrm{CaCO}_{3}$ due to the pozzolanic reaction in hardened cement paste; therefore the amount of C-S-H increases which promotes strength gain of concrete [2]. Also $\mathrm{SiO}_{2}$ and $\mathrm{Al}_{2} \mathrm{O}_{3}$ rich additives like zeolites can increase the amount of the C-S-H gel in concrete and reduce Portlandite by almost $50 \%$ at the concrete age of 3 and 28 days [3]. Pozzolanic reactions are slow thus for favourable reactions in UHSC heat treatment can be applied and the potential of supplementary cementitious materials containing high amount of amorphous $\mathrm{SiO}_{2}$ can be used in the concrete cured at elevated temperatures. Fine glass $(<25 \mu \mathrm{m})$ incorporated in concrete provides significant pozzolanic reactions in elevated temperatures even at early age [4]. The heat treatment of cement matrix leads to mineral composition change in the structure. Increased temperature during hardening intensifies the formation of $\mathrm{CAH}_{10}$ and $\mathrm{C}_{2} \mathrm{AH}_{8}$ at the temperature 60 and $80^{\circ} \mathrm{C}$, while at $110^{\circ} \mathrm{C}$ there is dense $\mathrm{C}_{3} \mathrm{AH}_{6}$ structure observed [5].

Gallucci concluded that concrete cured at elevated temperatures up to $60^{\circ} \mathrm{C}$ provides lower final strength caused by the C-S-H packing in nanoscale due to lose of bound water; therefore cement paste is coarser and more porous [6]. Derabla and Benmalek has published a research where self-compacting concrete with 50 
MPa strength has been heat treated at $60^{\circ} \mathrm{C}$ for $24 \mathrm{~h}$. This approach turned out to be cost effective in early age of concrete while in long term the compressive strength loss was observed comparing to reference concrete [7].

Yan and Cui have reported that HSC cured at elevated temperatures restraints the compressive strength development, if only Portland cement is used in mixture composition, while using pozzolanic materials the compressive strength of concrete increases two times at early age and continues to grow in long term [8]. Other research has tested effect of elevated temperature to high volume fly ash concrete and it was concluded that exposure to elevated temperature up to $300^{\circ} \mathrm{C}$ increased the compressive strength of concrete while treatment at higher temperature decreased the strength of concrete [9], [10].

There are negative aspects which must be considered in order to apply heat treatment to the UHSC. In some cases significant damages of surfaces were observed for specimens cured at elevated temperatures. It is explained by excessive deformation of the exposed surface layer of concrete [11]. This can cause microcracking of the surface; therefore reduction of mechanical properties and durability of concrete can be observed.

Another problem of HSC exposure to elevated temperatures is related to explosive spalling, when sudden and destructive breaking of surface layer occurs during heating of concrete [12]. This problem has been associated with dense structure of the HSC and UHSC and this leads to low permeability of the material. The evaporation of free water from the structure of such concrete is limited, which builds up inner pressure, and when the tensile strength of concrete is reached, the spalling of concrete surface destroys the structure of the material. The pore pressure begins at $105^{\circ} \mathrm{C}$, which corresponds to the water evaporation temperature, and the peak of pressure is reached at $220^{\circ} \mathrm{C}$, when either explosive spalling occurs or pore pressure attenuates [13]. This is important finding for understanding the properties of UHCP. It is recommended not to exceed curing temperature above $200^{\circ} \mathrm{C}$ to avoid the potential pressure building up to critical and reduce the risk of explosive spalling.

In current research two series of heat treatment regimes in curing processes of UHCP were investigated and $200^{\circ} \mathrm{C}$ was selected as the highest heat treatment temperature.

\section{MATERIALS AND METHODS}

Ultra high strength concrete (UHSC) mixture design was created using CEM I $42.5 \mathrm{~N}$ with Blaine fineness of $3787 \mathrm{~cm}^{2} / \mathrm{g}$. The maximal grain size of
UHSC filler was $2.5 \mathrm{~mm}$. Four fractions of fine sands were used: $0.3 / 2.5 \mathrm{~mm}, 0 / 1.0 \mathrm{~mm}, 0 / 0.3 \mathrm{~mm}$ and quartz powder to ensure compact structure of the UHCP. Elkem silica fume grade 971 (Fig. 1) and NanoSilica 999 (Fig. 2) were used as microfillers.

The mixture composition of UHSC is given in Table 1. The amount of cement was $800 \mathrm{~kg} / \mathrm{m}^{3}$, the $\mathrm{W} / \mathrm{C}$ was 0.25 , and water to cement paste (cement and silica fumes) ratio $\mathrm{W} /(\mathrm{C}+\mathrm{P})$ was 0.22 . To ensure workability of such low W/C UHCP mixture superplasticizer Sikament 56 was used $(2.5 \%$ from weight of cement). Micro silica fume was added $12.5 \%$ from the mass of cement $\left(100 \mathrm{~kg} / \mathrm{m}^{3}\right)$ and nanosilica $-2.5 \%\left(20 \mathrm{~kg} / \mathrm{m}^{3}\right)$ respectively.

The mixing procedure of UHCP was the following: all dry components except NanoSilica were mixed together for $90 \mathrm{~s}$ to obtain homogenous mixture of dry components.

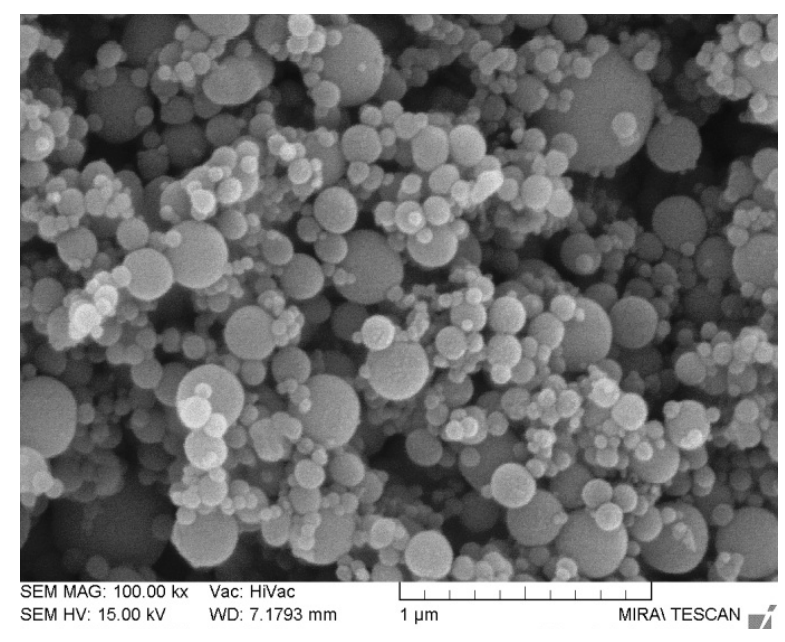

Fig. 1. Scanning electron microscope image of Elkem micro silica fume grade 971 .

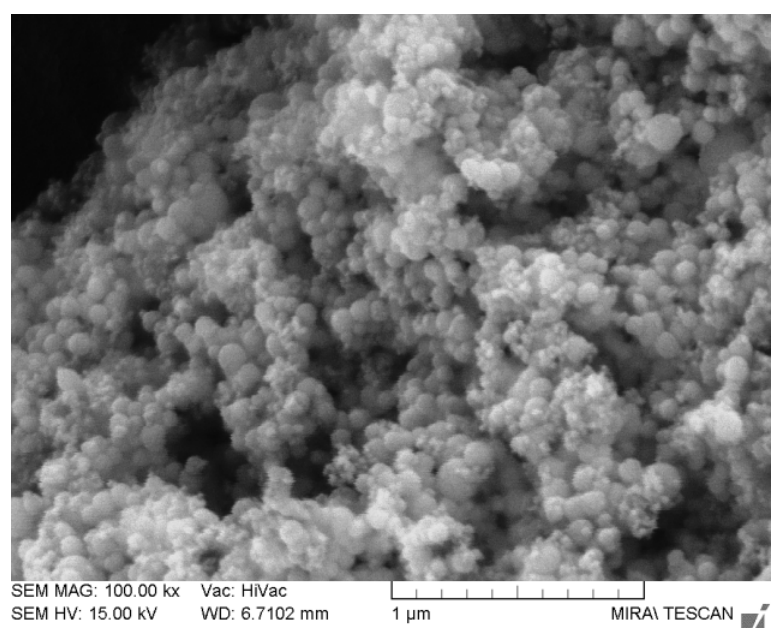

Fig. 2. Scanning electron microscope image of Elkem nano silica fume NanoSilica 999. 
Then NanoSilica as water suspension (with ratio $1: 2$ ) and $75 \%$ of water were added to the mixture of dry components and mixed together for $120 \mathrm{~s}$. In the last stage superplasticizer with the rest of water $(25 \%)$ were added and mixed until homogenous and workable mixture was obtained. The total mixing time of UHCP was 6 minutes. 3 batches were prepared with 71 of UHCP in each batch. The UHCP was cast in 18 cubical moulds with dimensions $5 \times 5 \times 5 \mathrm{~cm}, 4$ cubical moulds with dimensions $10 \times 10 \times 10 \mathrm{~cm}$ and 9 prismatic moulds with dimension of $4 \times 4 \times 16 \mathrm{~cm}$. After casting of UHCP in moulds samples were vibrated for $10 \mathrm{~s}$.

Table I

Mixture composition of UHCP

\begin{tabular}{|c|c|}
\hline Mixture composition & $\mathrm{kg} / \mathrm{m}^{3}$ \\
\hline Cement CEM I 42,5 N & 800 \\
\hline Sand $0.3 / 2.5 \mathrm{~mm}$ & 510 \\
\hline Sand $0 / 1.0 \mathrm{~mm}$ & 480 \\
\hline Sand $0 / 0.3 \mathrm{~mm}$ & 100 \\
\hline Quartz powder & 100 \\
\hline Micro silica fume & 100 \\
\hline Nano silica fume & 20 \\
\hline Superplasticizer & 20 \\
\hline Water & 200 \\
\hline $\mathrm{W} / \mathrm{C}$ & 0.25 \\
\hline $\mathrm{W} /(\mathrm{C}+\mathrm{P})$ & 0.22 \\
\hline
\end{tabular}

Samples were remoulded after 3 days of hardening and cured at standard conditions in water $\left( \pm 20^{\circ} \mathrm{C}\right)$ or early heat treatment regime was applied. Four heat treatment conditions at temperature 50,100,150 and $200^{\circ} \mathrm{C}$ were tested for UHCP. The heat treatment was applied after remoulding the samples (on $3^{\text {rd }}$ day) or at the age of 27 days after standard curing conditions (Table 2). The temperature increase during heating was $10^{\circ} \mathrm{C} / \mathrm{min}$, samples were treated at the maximal temperature for $4 \mathrm{~h}$ and then cooled to room temperature.

Table II

Heat treatment regimes applied to UHCP

\begin{tabular}{|c|c|c|}
\hline Sample ID & Concrete age, $d$ & $\begin{array}{c}\text { Heat treatment, } \\
{ }^{\circ} \mathrm{C}\end{array}$ \\
\hline Ref & - & - \\
\hline HT3-50 & 3 & 50 \\
\hline HT3-100 & 3 & 100 \\
\hline HT3-150 & 3 & 150 \\
\hline HT3-200 & 3 & 200 \\
\hline HT27-50 & 27 & 50 \\
\hline HT27-100 & 27 & 100 \\
\hline HT27-150 & 27 & 150 \\
\hline HT27-200 & 27 & 200 \\
\hline
\end{tabular}

The compressive strength of concrete was tested according to LVS EN 12390-3. Compressive strength was determined for the specimens sized $50 \times 50 \times 50 \mathrm{~mm}$. Depth of penetration of water was tested according to LVS EN 12390-8. Concrete specimens with dimensions $100 \times 100 \times 100 \mathrm{~mm}$ were tested under pressure of $500 \mathrm{KPa}$ for $72+2 \mathrm{~h}$. Water absorption was determined according to EN 1097-6. Scanning electron microscope (SEM) (Tescan Mira/LMU) was used for microstructural research and the mineralogical composition was determined with XRD (PAN analytical X'Pert PRO).

\section{RESULTS AND DISCUSSION}

The density of obtained UHSC was $2.32 \mathrm{~g} / \mathrm{cm}^{3}$ and after heat treatment at temperature $200^{\circ} \mathrm{C}$ it decreased to $2.25 \mathrm{~g} / \mathrm{cm}^{3}$ which can be attributed to the evaporation of free water from the structure of UHSC. The SEM image of microstructure for reference sample (Ref) is given in Fig. 3 and for HT3-200 in Fig. 4. In both images dense microstructure of specimens was observed and the unreacted silica fume particles were detected. The significant difference of microstructure after heat treatment cannot be observed by SEM images; however, microstructure of the heat treated samples looks more porous compared to the reference sample. It could be explain by dehydration of C-S-H gel during heat application.

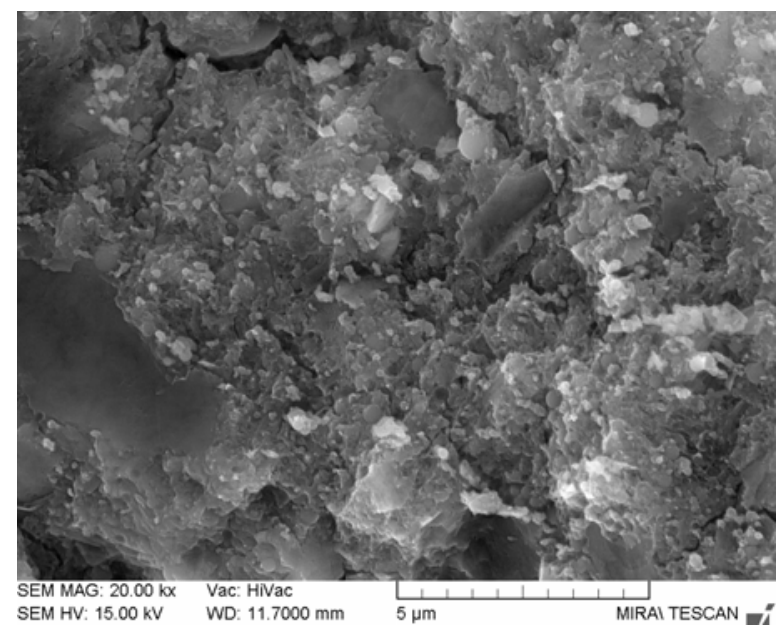

Fig. 3. The microstructure of UHSC cured at standard conditions at the age of 4 days (Ref). 


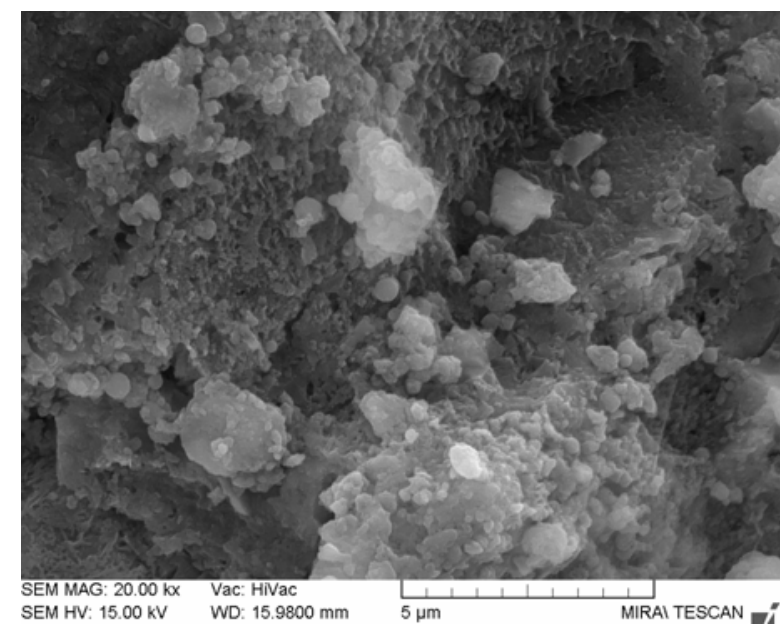

Fig. 4. The microstructure of UHSC cured at $200{ }^{\circ} \mathrm{C}$ for $4 \mathrm{~h}$ at the age of 4 days (HT3-200).

The results of compressive strength are given in Table 3. The early heat treatment of UHSC was beneficial for early compressive strength. The compressive strength for reference (Ref) UHSC was $77 \mathrm{MPa}$ at the age of 4 days. The heat treatment even at $50^{\circ} \mathrm{C}$ for 4 hours increased the compressive strength up to $95 \mathrm{MPa}$ but significant strength gain was observed for UHSC treated at temperature $100^{\circ} \mathrm{C}(130$ $\mathrm{MPa})$.

The heat treatment at early age in the temperature above $100^{\circ} \mathrm{C}-143 \mathrm{MPa}\left(150^{\circ} \mathrm{C}\right)$ and $145 \mathrm{MPa}$ $\left(200^{\circ} \mathrm{C}\right)$ was less effective. However, the early heat treatment did not provide further compressive strength increase during ageing of the concrete. At the age of 28 days compressive strength of reference increased to $123 \mathrm{MPa}$ while for HT3-50 the decrease of compressive strength to only $117 \mathrm{MPa}$ was observed-. HT3-100 provided almost the same compressive strength as Ref at the age of 28 days (124 MPa) while samples cured at 150 and $200^{\circ} \mathrm{C}$ (HT3-150 and HT3200) provided compressive strength increase to 137 and $144 \mathrm{MPa}$ respectively.

Table III

Compressive strength results of UHSC

\begin{tabular}{|c|c|c|c|c|}
\hline \multirow{2}{*}{ Sample ID } & \multicolumn{2}{|c|}{$\begin{array}{c}\text { Compressive } \\
\text { strength, MPa }\end{array}$} & \multicolumn{2}{c|}{ Strength index, \% } \\
\cline { 2 - 5 } & $4^{\text {th }}$ day & $28^{\text {th }}$ day & $4^{\text {th }}$ day & $28^{\text {th }}$ day \\
\hline Ref & 77 & 123 & 100 & 100 \\
\hline HT3-50 & 95 & 117 & 119 & 95 \\
\hline HT3-100 & 130 & 124 & 141 & 101 \\
\hline HT3-150 & 143 & 137 & 146 & 110 \\
\hline HT3-200 & 145 & 144 & 147 & 115 \\
\hline HT27-50 & - & 138 & - & 111 \\
\hline HT27-100 & - & 144 & - & 115 \\
\hline HT27-150 & - & 150 & - & 118 \\
\hline HT27-200 & - & 153 & - & 120 \\
\hline
\end{tabular}

The heat treatment for UHSC at the age of 27 days was beneficial to the compressive strength increase for all heat treatment regimes. The compressive strength of samples treated at temperature $200{ }^{\circ} \mathrm{C}$ in age of 27 days increased up to $153 \mathrm{MPa}$ comparing to the reference samples $(123 \mathrm{MPa})$. This indicates the importance of initial water curing at standard conditions of UHSC and understanding the necessity for heat treatment at proper age of the concrete. The strength index increased to 111 to $120 \%$ compared to the reference by applying heat treatment at the UHSC aged 27 days

The relative strength increase of UHSC related to the heat treatment temperature and the age of UHSC, when heat treatment was applied, is given in Fig 5. The initial compressive strength increase at the age of 4 days was significant $(119 \%)$ even at the heat treatment at $50{ }^{\circ} \mathrm{C}$, while the strength at 28 days decreased to $95 \%$ comparing to the reference. The compressive strength increase at the age of 28 days for samples, which were heat treated at the age of 27 days, was almost linear and strength increase was observed for every sample treated in elevated temperature.

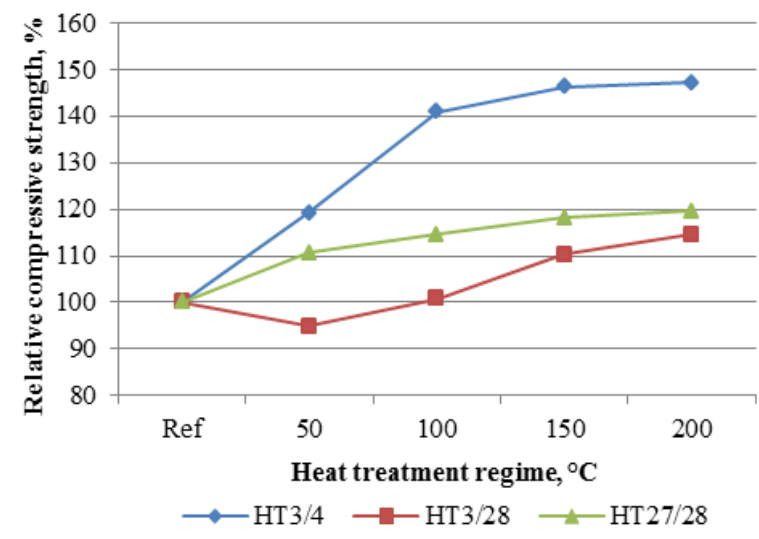

Fig. 5. Relative strength index of heat treated UHSC samples comparing to reference samples with standard curing regime.

The water absorption of UHSC was from 2.2 to $3.5 \%$, and it was not affected by the heat treatment regime. The water penetration under pressure of $5 \mathrm{Bar}$ was not detected for untreated UHSC at the age of 28 days $(0 \mathrm{~mm})$ while for heat treated samples HT3-200 the water penetration was $3 \mathrm{~mm}$ in average and up to 8 $\mathrm{mm}$ in some parts. This could be explained by the crack pattern of UHSC which appeared after heat treatment and thermal stresses, induced by the increased temperature and drying conditions, and was clearly seen after water penetration test (Fig 6). 


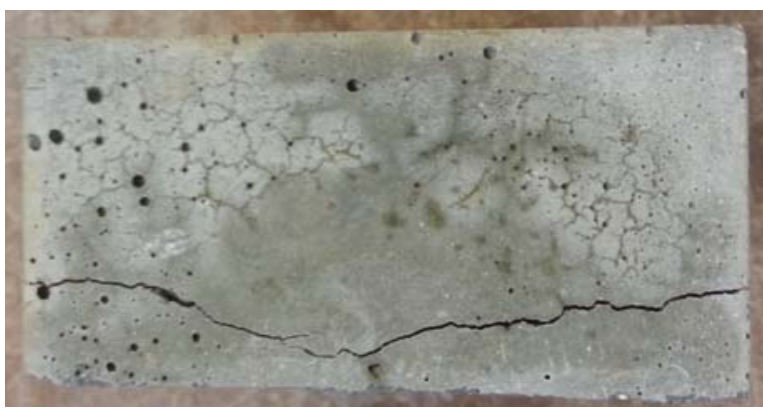

Fig. 6. The microcrack pattern of split UHSC sample cured at $200{ }^{\circ} \mathrm{C}$ for $4 \mathrm{~h}$ (HT3-200)

The XRD patterns of reference and HT3-200 are given in Fig. 7 and Fig. 8. The results indicate that UHSC cured at standard conditions has quartz (Q), larnite $(\mathrm{L})$ and plagioclase $(\mathrm{P})$ minerals, while in heat treated sample calcite $(\mathrm{C})$ has been detected, which could indicate the carbonization of free portlandite $\left(\mathrm{Ca}(\mathrm{OH})_{2}\right)$ and therefore possibly increases the early age strength of UHCP. The reduction of portlandite could restrict the pozzolanic reaction; therefore long term strength gain is limited for heat treated samples.

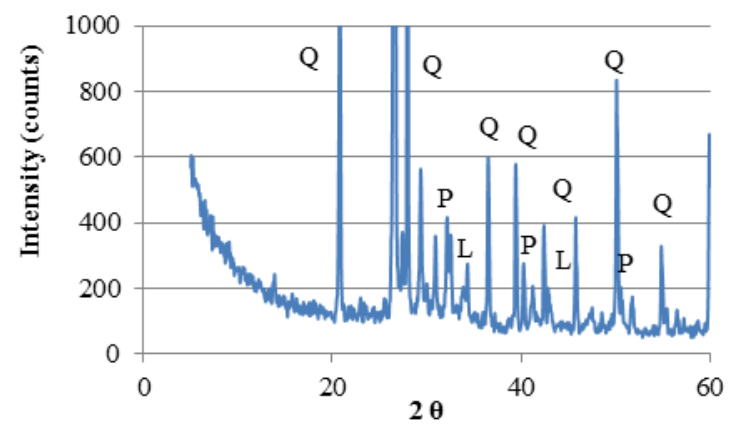

Fig. 7. XRD pattern of UHSC cured at standard conditions (Ref) at the age of 28 days.

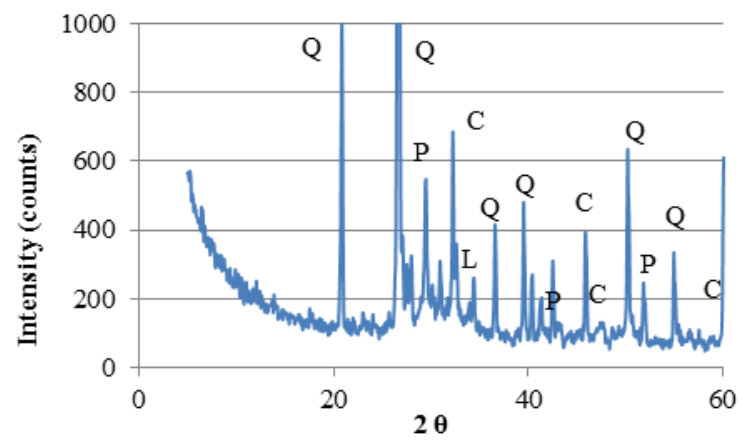

Fig. 8. XRD pattern of UHSC cured at $200{ }^{\circ} \mathrm{C}$ for $4 \mathrm{~h}(\mathrm{HT} 3-200)$ at the age of 28 days.

\section{CONCLUSIONS}

It was concluded that the early heat treatment at the temperatures ranging from 50 to $200^{\circ} \mathrm{C}$ is effective to gain early age strength of UHSC, while in the long term curing in temperature from 50 to $100^{\circ} \mathrm{C}$ was not effective and strength reduction was observed comparing to UHSC cured in standard conditions. Early heat treatment was effective in temperature range from 150 to $200^{\circ} \mathrm{C}$, when compressive strength at 28 days increased from 110 to $115 \%$ comparing with reference concrete. The heat treatment of UHSC at the age of 27 days increased its compressive strength from 111 to $120 \%$, and was beneficial with all heat treatment regimes. The heat treatment caused microcrack pattern of UHSC which reduced resistance to water penetration under pressure. In the mineralogical composition of UHSC after heat treatment calcite $\mathrm{CaCO}_{3}$ was detected, which indicates the carbonization of free $\mathrm{Ca}(\mathrm{OH})_{2}$ and is one of reasons for early age strength gain of UHSC.

\section{ACKNOWLEDGMENT}

The research leading to these results has received the funding from the Latvian state research programme under grant agreement „INNOVATIVE MATERIALS AND SMART TECHNOLOGIES FOR ENVIRONMENTAL SAFETY, IMATEH".

\section{REFERENCES}

[1] B. Graybeal, "UHPC Making Strides - Vol. 72 - No. 4 - Public Roads," $2009 . \quad$ [Online]. Available: http://www.fhwa.dot.gov/publications/publicroads/09janfeb/0 3.cfm. [Accessed: 24-Mar-2015].

[2] D. Vaičiukyniene, V. Vaitkevičius, A. Kantautas, and V. Sasnauskas, "Effect of AlF3 Production Waste on the Properties of Hardened Cement Paste," Mater. Sci., vol. 18, no. 2, pp. 187-191, Jun. 2012.

[3] D. Vaičiukyniene, G. Skipkiunas, M. Daukšys, and V. Sasnauskas, "Cement hydration with zeolite-based additive," Chemija, vol. 24, no. 4, pp. 271-278, 2013.

[4] M. Mirzahosseini and K. A. Riding, "Effect of curing temperature and glass type on the pozzolanic reactivity of glass powder," Cem. Concr. Res., vol. 58, pp. 103-111, Apr. 2014.

[5] I. Demidova-Buizinene and I. Pundiene, "Effect of Amount of Deflocculant on Change in Physicomechanical Properties of Medium-Cement Heat-Resistant Concretes During Drying and Heat Treatment," Refract. Ind. Ceram., vol. 55, no. 2, pp. 121127, Aug. 2014.

[6] E. Gallucci, X. Zhang, and K. L. Scrivener, "Effect of temperature on the microstructure of calcium silicate hydrate (C-S-H)," Cem. Concr. Res., vol. 53, pp. 185-195, Nov. 2013.

[7] R. Derabla and M. L. Benmalek, "Characterization of heattreated self-compacting concrete containing mineral admixtures at early age and in the long term," Constr. Build. Mater., vol. 66, pp. 787-794, Sep. 2014.

[8] P. Yan and Q. Cui, "Effects of curing regimes on strength development of high-strength concrete," Kuei Suan Jen Hsueh Pao/Journal Chinese Ceram. Soc., vol. 43, no. 2, pp. 133-137, 2015.

[9] M. S. Khan and H. Abbas, "Effect of elevated temperature on the behavior of high volume fly ash concrete," KSCE J. Civ. Eng., Dec. 2014.

[10] K. N. Vishwanath Prof., S. Narayana Dr., and V. Bindiganavile Dr., "Influence of sustained elevated temperature on fly ash concrete," Indian Concr. J., vol. 88, no. 1, pp. 26-32, 2014.

[11] A. Omran, Z. He, and G. Long, "Heat damage of steam curing on the surface layer of concrete," Mag. Concr. Res., vol. 64, no. 11, pp. 995-1004, Nov. 2012. 
Girts Bumanis, et al./ Environment. Technology. Resources, (2015), Volume I, 22-27

[12] L. Phan and N. Carino, "Effects of test conditions and mixture proportions on behavior of high-strength concrete exposed to high temperatures," ACI Mater. J., vol. 99, no. 1, pp. 54-66, 2002
[13] L. T. Phan, "Pore pressure and explosive spalling in concrete," Mater. Struct., vol. 41, no. 10, pp. 1623-1632, 2008. 